\title{
Kommentierte
}

\section{Studien 2012-2016}

"Verschiedenes"

2015

- Chirurgisches Management nach Embolisation gastrointestinaler und abdomineller Blutungen

https://www.springermedizin.de/link/10.1007/s00104-014-2978-5

\section{3}

- Prophylaktische Netzimplantation nach Laparotomie bei Risikopatienten

https://www.springermedizin.de/link/10.1007/s00104-013-2546-4 